\title{
Isthmic Agenesis and Thyroid Hemiagenesis Associated with Thyroiditis: A Case Report
}

\author{
Tirtha Lal Upadhyaya ${ }^{1}$, Shyam Sundar Parajuly ${ }^{2}$, Roshan Pangeni ${ }^{3}$ \\ ${ }^{1}$ Head of the Department, Department of Medicine, Gandaki Medical College and Teaching Hospital, \\ Pokhara, and Director of Diabetes, Thyroid and Endocrinology Care Centre, New Road Pokhara, Nepal, \\ ${ }^{2}$ Department of Ultrasound, Western Regional Hospital, Pokhara Academy of Health and Sciences, \\ Pokhara, Nepal
}

\begin{abstract}
Congenital thyroid anomalies are rare. Developmental anomalies may be in the form of unilateral or bilateral hypoplasia or agenesis of one or both lobes of thyroid with or without isthmic agenesis. Most of the times when they are detected incidentally already have associated thyroid diseases. We report a 36- year-old female presented with right thyroid hemiagenesis and isthmic agenesis associated with thyroiditis in left lobe of thyroid.
\end{abstract}

Key Words: Agenesis, congenital, ultrasound, thyroid

\section{Introduction}

Hemiagenesis of thyroid lobe is a rare embryological disorder which results from failure of one lobe of thyroid development. Most of the time they are detected either by clinical symptoms with associated thyroid diseases or by incidental findings on imaging or by obvious anatomical variations. Embryological development of the thyroid gland starts in the primitive pharynx in form of an invagination of the endoderm which grows ventrally while remaining attached to the pharyngeal floor. This rudiment will then migrate to its actual anatomical position that is anterior to the pharynx and after that it begins to grow laterally to create the bilobed thyroid gland ${ }^{1}$.

Congenital anomalies of thyroid may be either by abnormal descent of the gland or by incomplete genesis of a lobe; however the exact etiopathologies of the hemiagenesis is still unclear $^{2}$. Most of the

Corresponding Address:: Dr. Tirtha Lal Upadhyaya, MD Associate Professor, Head of the Department, Department of Medicine Gandaki Medical College \& Teaching Hospital, Pokhara, Nepal E-mail: tirtha77@hotmail.com cases are sporadic, a few may be familial and there may be a genetic predisposition. These patients may depicit normal thyroid lobe with euthyroidism ${ }^{3}$, and both hypothyroidism ${ }^{4}$ and hyperthyroidism ${ }^{5,6}$. Hemiagenesis of thyroid was first reported in the year of 1852 by Handsfield Jones ${ }^{7}$. Left sided hemiagenesis is quite common than the right with a ratio of $4: 1$ and female predominance with a ratio of $3: 1^{8}$. Very few literatures have been published in scientific journal about this rare developmental anomaly from our country. Herein we report an uncommon case of 36-year-old female with right sided hemiagenesis of thyroid with isthmic agenesis associated with Thyroiditis.

\section{Case Report}

A 36-year-old woman gravid 3, para 2 came to our centre for regular body check up. She had a complain of throat pain with whole body muscular pain. She was a regular patient for a renowned hospital in Kathmandu. She had a medication history of taking $75 \mathrm{mcg}$ thyronorm per day. This time she came to our centre as convenient to her. Her body weight was $63 \mathrm{~kg}$, height, $150 \mathrm{~cm}$, Body Mass Index was 28, and Blood pressure as recorded 


\section{CASEREPORT @@OPENACOESS}

was $120 / 90 \mathrm{mmof} \mathrm{Hg}$. She had undergone cesarean section for her second child 6 years ago. On physical examination the thyroid gland was nonpalpable on the left side. Serum thyroid hormones were mildmoderately low; serum free T3 was $1.9 \mathrm{pg} / \mathrm{ml}$ (normal range: $2.3-4.2 \mathrm{pg} / \mathrm{ml}$ ) and free T4 was 0.65 $\mathrm{ng} / \mathrm{ml}$ (normal range: $0.89-1.8 \mathrm{ng} / \mathrm{ml}$ ) and $\mathrm{TSH}$ 26.00. (3rd Generation Ultrasensitive TSH; Normal range 0.35_5.29). Antithyroglobulin and anti thyroperoxidase autoantibodies were negative.

Ultrasound was performed by Esaote My Lab 40 machine equipped with $12.5 \mathrm{MHz}$ linear transducer. Grey Scale US revealed no thyroid tissue on the right side (white arrow heads in panel C) with partial or absence of isthmus (Figure 1, panel A). Left lobe of thyroid revealed slightly heterogenous and coarse parenchymal echotexture with no increased in parenchymal vascularity in color Doppler imaging (Figure 1; Panel B and C). With the diagnosis of hemiagenesis of right lobe of thyroid and agenesis of isthmus with features of thyroiditis in left lobe ultrasound report was dispatched. She was managed by medicine with $100 \mathrm{mcg}$ dose of thyronum follow up after three months revealed normal level TSH and no abnormal lymphnodes with no complaint.
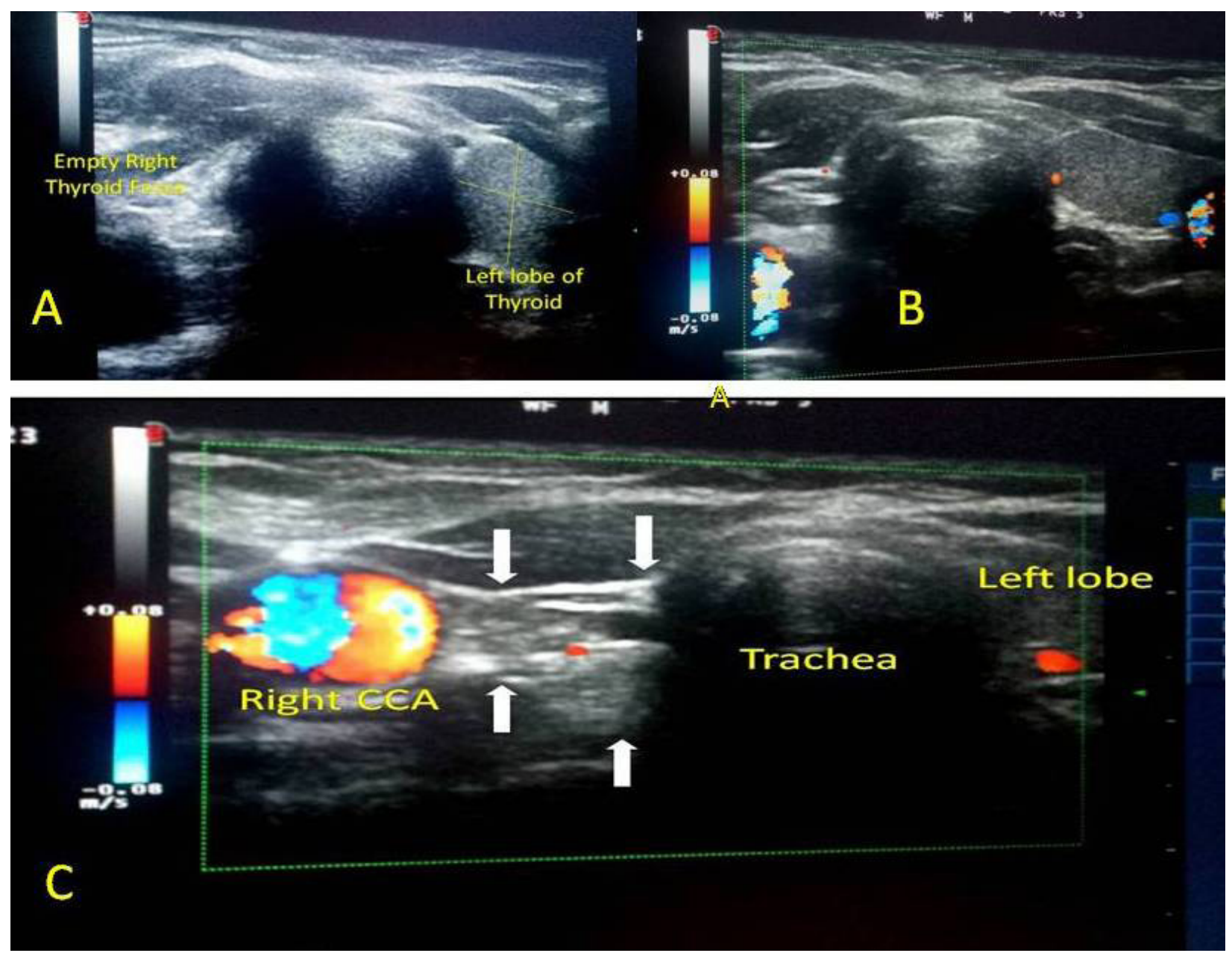


\section{Discussion}

Thyroid hemiagenesis is a rare congenital anamoly with absence of a lobe or a lobe along with the isthmus. Embroylogically it develops in the midline from the pharyngeal floor at the foramen caecum. ${ }^{9}$ The true prevalence of thyroid hemiagenesis is yet unknown, however few study revealed that estimated prevalence rate to be ranged between 0.05 and $0.2 \%{ }^{10}$ with the female predominance with the commonest site being the left lobe as in our case. A study conducted by Ruchala et al in $2010^{11}$ concluded that hemiagenesis of thyroid were more likely to develop thyroid pathology. The most frequent associated thyroid disorders according to Ruchala et al. were thyroid nodules and autoimmune thyroid diseases. Simple goiter and nonautoimmune subclinical hypothyroidism were less often observed. In our case features of thyroiditis were reported on grey scale and color doppler songrams. Ultrasound as being the firstline modality to image the thyroid gland; is feasible, convenient and cheaper than MRI or scinitgraphy. As in our case agenesis of right lobe of thyroid and isthmus was established by ultrasound. Thyorid hemiageneis though is a rare abnormality, routine exams or screening on ultrasound would be a great helpful for the endocrinologist and other physician to rule out associated thyroid nodules or other thyroid diseases.

\section{References}

1. Maiorana R, Carta A, Floriddia G, Leonardi D, Buscema M, Sava L, et al. Thyroid hemiagenesis: prevalence in normal children and effect on thyroid function. J Clin Endocrinol Metab. 2003;88(4):153436.

2. Castanet M, Leenhardt L, Léger J, Simon-Carré A, Lyonnet S, Pelet A, et al. Thyroid hemiagenesis is a rare variant of thyroid dysgenesis with a familial component but without Pax8 mutations in a cohort of 22 cases. Pediatr Res. 2005; 7:908-13.

3. Aslaner A, Aydin M, Ozdere A. Multinodular goiter with thyroid hemiagenesis: A case report and review of the literature. Acta Chir Belg. 2005;105:528-30

4. Tonacchera M, Banco ME, Montanelli L, Di Cosmo C, Agretti P, De Marco G, et al. Genetic analysis of the PAX8 gene in children with congenital hypothyroidism and dysgenetic or eutopic thyroid glands: Identification of a novel sequence variant. Clin Endocrinol (Oxf) 2007; 67:34-40.

5. Lee IT, Sheu WH, Lin SY. Familial form of thyroid dysgenesis: Report of thyroid hemiagenesis with accompanying Graves' disease in a woman whose daughter has thyroid agenesis. Horm Res. 2003;59:47-9.

6. Baldini M, Orsatti A, Cantalamessa L. A singular case of Graves' disease in congenital thyroid hemiagenesis. Horm Res. 2005;63:107-10.

7. Zachariah SK, Narayanan P, Mathew NV, Krishnankutty SL. Hemiagenesis of the right lobe and Isthmus of the thyroid presenting as multinodular goitre. Res Endocrinol 2014;2014:5.

8. Shaha AR, Gujarati R. Thyroid hemiagenesis. J Surg Oncol 1997; 65:137-40.

9. Zachariah SK, Narayanan P, Mathew NV, Krishnankutty SL. Hemiagenesis of the right lobe and Isthmus of the thyroid presenting as multinodular goitre. Res Endocrinol 2014;2014:5

10. Sthapak E, Gajbe UL, Wanjari SP, Upadhyaya VD, Kumar B. Thyroid Agenesis: A case Report with Review of Literature. World J Endoc Surg 2012;4(3):99-01

11. Ruchala M, Szczepanek E, Szaflarski W, Moczko J, Czarnywojtek A, Pietz L et al. Increased risk of thyroid pathology in patients with thyroid hemiagenesis: results of a large cohort case-control study. Eur J Endocrinol. 2010;162:153-60. 